\title{
Student's Interactivity in School Assembly: The Case of Master's Degree on Creation and Innovation Management
}

\author{
Adriana Margarita Pacheco Cortés, Elba Patricia Alatorre Rojo, Carlos Manuel Pacheco Cortés, Daniel Montes Ponce* \\ Sistema de Universidad Virtual, Universidad de Guadalajara, Guadalajara, México \\ *Corresponding author: adrianap@cencar.udg.mx
}

Received December 30, 2014; Revised January 30, 2015; Accepted February 04, 2015

\begin{abstract}
The purpose of this study was to identify the types of participation within the discussion forum activity module through messages posted by alumni enrolled to the Master's Curriculum on Creation and Management of Innovation (MGGI as acronym in Spanish). The forum enabled was named "innovation" and it recorded the discussion activity and classified each of the interactions according to the teaching role, cognitive or social presence (dimension). The research approach was qualitative; we used conversation analysis to identify dimensions which messages are included. Fifteen participating students conformed the sample of analysis, they contributed with 47 messages (units), without assessment intervention (but generic only, not counted). As the first finding, a type of interaction by discussion was identified. The second finding was a communicational network in a Sociogram representation (graph drawing plots the structure of interpersonal relations in a MGGI group situation). The third and last finding was a set of messages classified by dimensions. The alumni discussed to each other about the innovation topic and there was a meaningful construction as well as the expected interactions.
\end{abstract}

Keywords: virtual, interaction, forum, dialoguing, knowledge-constructing, learning

Cite This Article: Adriana Margarita Pacheco Cortés, Elba Patricia Alatorre Rojo, Carlos Manuel Pacheco Cortés, and Daniel Montes Ponce, “Student's Interactivity in School Assembly: The Case of Master's Degree on Creation and Innovation Management.” American Journal of Educational Research, vol. 3, no. 2 (2015): $152-158$. doi: 10.12691/education-3-2-7.

\section{Introduction}

One System of Virtual Campus (in Spanish: Sistema de Universidad Virtual, or SUV) has its own academic offer with several formative programs online based and into the distance, that require all these the technologies of information and communication for the education in order to structure virtual environments. In the level of postgrade, the SUV offers the master's degree on management of public services into virtual environments, the master's degree on generating and managing of innuendo, and the doctorate on systems and educational environments.

In the level of pre-grade (minor + major), the SUV offers the bachelor's degree on education, the bachelor's degree on technology and informatics, the bachelor's degree on Biblioteconomy, the bachelor's degree on culture management, the bachelor's degree on citizenry security, and the bachelor's degree on management into the organizations. In addition, the SUV has a baccalaureate program and continual education by brief courses and diplomas in order to provide attention to different sector of the Mexican society, that are all those required by the government as much as by the particulars.

The post-grade programs into the SUV, this year, are structured on seminaries, workshops, and laboratories that all these are given on-line, these virtual spaces have tools and resources designed for each educative purpose. These post-grade programs are well known because the enrolled alumni are expected to organize their time, dedicating it for the independent research, for discussion into academic groups inside virtual forums most of times, for management of their own project with tutorial accompaniment, and for continuous diffusion of their findings; these students use their capabilities to structure projects over their context following the objective of gaining experiences of substantial learning and to develop their own capability for responding to the requirements of their environment.

On October the 1st, 2010, the master's degree on generating and managing of innuendo is approved by the local council of SUV ("Maestría en Generación y Gestión de la Innovación”, or MGGI) which one started on the first scholastic term of 2011 (February to July). At February 8th began a course named Introduction to Virtual Technologies as introductory course across the Modular Object-Oriented Dynamic Learning Environment (MOODLE), where professors and alumni interacted in triangle conduct (teacher to student, and one student to another), and which one lasted for two weeks following the competence "Use the MOODLE tools to perform practices of individual communication and collaborative communication, according to labor requirements or homework reports. 
The alumni enrolled into the MGGI were 15: nine of them, inside the State of Jalisco, and the other six, in the rest of the Republic; all of them are employees in different areas, they have a bachelor degree and a qualification between 80 and 100 percent; the age range goes from 24 and 60 years old; they have skills useful to take the MGGI studies due to the academic area request: first of all, they must to depart from a protocol of research; second, they need to be self-managed, intellectually capable, and culturally inquisitive; third, they need to include procedures of technological innuendo; and fourth, they have to try developing their own intellect. Into the field of technology: they need to demonstrate skills for internet surfing, to work on Microsoft Office (Word, Excel, Power Point, Access, and Outlook), as much as to know how to log into the MOODLE.

On the other hand, online forums are exposed as environments for interactivity between distant individuals in order to encourage discussion, motivation, socialization, assessment, and feedback, that contribute all those to the learning; departing from the argumentative dialog and the pragmatic dialog, as much as from the played role by the professor and the alumni into the virtuality.

\section{Material and Methods}

Among the publications made about online forums are: Perera \& Torres (2005) who investigated the analysis of pedagogical, social and cognitive skills in these online forums, describe a constructive and spaces that facilitate social construction of knowledge; these authors stated that students are willing to share ideas, but not to deepen their knowledge through discussion that the forum supports student learning, but they find it difficult to say what they have learned and experiences from applying learned in the field of actual practices.

Among these publications, the authors Garcia \& Perea (2007) stated that in a forum, the sequence of speech is a dynamic process that must be analyzed over time and follows a branched sequence so that for each string of messages opens up many possibilities that can be more or less participatory in terms of interventions of tutors or students, this process assumes that the training through the Internet, the teacher performs functions tutorials, they must have a special sensitivity to recognize potential that online speech is to foster in students more engaged.

Similarly, Aires et al (2006) noted that discussion forums are sites that promote: the presentation, the discussion and the deepening of knowledge through the written language; in these learning environments are a mediating instrument by excellence because shared knowledge, feelings and attitudes, contributes to virtual community cohesion.

\subsection{The Research Problem}

At the beginning of the course was opened five virtual forums called: (a) news and announcements, (b) virtual coffee, (c) questions, support and feedback, (d) expectations of the course presentations and (e) innovation (activity to the discussion). The news and announcements forum is a digital whiteboard to write news, make announcements, inform students that the counselor wants to communicate, that they know what will happen during the course of the week or any special news. In virtual coffee forum, the students are presented, make questions, offer help each other and comments about their hobbies and course expectations. This space is for socialization encouraged to participate in this space get to know students, have with an area for recreation, they externalize what they are most passionate, external queries, suggestions and comments in this place is conducive to the support and solidarity or camaraderie, among others.

Also, in one of those spaces, they present their expectations regarding the course, all interactions of these three forums are social expectations except to which students individually write what they expect from this course; each virtual forum message includes the participant's name and photograph, so that students are looking at the person they are talking (through textual speech), discuss or with whom they are addressing.

The business forum for the debate is a question to generate/trigger interaction, the wording of the statement is as follows: "Without consulting any book or information source in your own words describe what is innovation? Once you answer the question will be answered with a partner (a) and because they justify or argue for or against the advice of his companion. It is necessary to participate on the scheduled dates because we will only have two weeks to miss this topic and the discussions and views of their peers. I welcome your participation.”

The 15 students of MGGI answered the question but the next problem arises, what happens with the interactions in the forum? What kind of ideas are in the debate? it is unknown how are the interactions of discussion between MGGI's students, how the students constructing their knowledge? who have prior knowledge about the innovation topic?, how to classify the units that occur in the virtual forum with those students.

After reviewing different experiences and models for the study of interactions in virtual environments, some considerations were identified among which is mentioned that there is this: A large number of categories established for this type of study, very complex interactions, their meanings and units of analysis. Among the models tested are the Garrison \& Anderson (2005), that of Gunawardena, Lowe \& Anderson (1997), that of Henri (1992), in the first model was used: component, category and indicators in second model is used: stages and categories, in the third model dimensions are used, definitions and indicators, among others.

Based on the model analysis the decision was made to address and accommodate three dimensions for the forum to analyze the activity called innovation for discussion. According to the model of Garrison, Anderson \& Archer (2000), we used the following dimensions: (a) Social Presence, (b) Teaching Presence, and (c) Cognitive Presence.

\section{Social Presence}

For Garrison, Anderson \& Archer (2001) social presence include all those interactions that foster the creation of a dynamic group, promote social relationships, express emotions, and in which the student group is stated as such. Virtual communication requires interaction among participants to project itself as a learning community. 
This dimension includes acknowledgments, contributions entertainment, jokes, greetings, expressing emotions, keep a message, ask questions of socialization, and refer to us as a group, which imply its cohesion (Garcia \& Perea, 2007); social presence helps the student to be identified and known by the learner, as he is, not only for their products, but also through his messages, his writing style, their interests and interactions, but the messages are related to the topic.

Job of the professor is to allow and encourage closer relationships among peers and with him; these interactions help to establish some empathy between them and, in some ways, because a special interest in teaching students the process, which results in personalized advice tailored to your specific needs and processes. The student also establishes relationships with peers and his professor, which may persist until after graduating from the program, with similar training bases and the possibility of mutual support and the social networking discipline.

\section{Teaching Presence}

For Moore \& Anderson (2003) lead professor's knowledge to student through a learning environment based on activity that allows them freedom and initiative to achieve their own goals. In this case, virtual forum is encouraging and stimulating interaction among students, an activity was proposed for discussion under the topic What is innovation?, so that students have the initiative to participate by writing messages linked those of their peers.

In this sense, the advisor on the discussion forums prosecutes his care to the learning process and does so in three stages, as a designer, facilitator of a social environment that drives learning, and content expert who knows how to bring students to this knowledge (Anderson, Rourke, Garrison \& Archer, 2001). The author describes the three stages as follows:

Designer $\rightarrow$ The presence of the professor begins long before teaching the course, with the responsibility of designing and organizing it ideal activity to take place in pairs or in teams, and with it, planning the process, structure, timing, its components, interactions and evaluations. Thus, in this category, the teacher presence focuses on constructing and on developing the course materials that support, resources, learning objects, notes, lectures, and readings, i.e. efficient in making the course material and advisory activities.

Social environment provider $\rightarrow$ At designing the course, the professor should think in terms of collaboration, which means humanizing the learning environment. Based on the premise that learning occurs in a cultural-social context and that knowledge is socially constructed (Vygotsky (1987), Bruner, 1996, Wertsch \& Stone, 1999). These authors inferred that instructional design includes the following:

- Group Dynamics filing a specific forum. This speeds up the process of mutual knowledge and considers the affective dimension of all participants;

- Facilitator messages with a basis of respect for the person, their individual and group processes for a more realistic work environment of mutual trust and security of your acceptance into the group;

- Mutual tasks that allow the process of cohesion of the participants' purposes and needs;
- These works involve the collaboration team, are asked students to assume a role in the execution of the task and record at least three specific roles in the team: the moderator, who facilitates the group's work, gives direction review the instructions and is subject to the limits of time, the synthesizer, which summarizes the responses from everyone and prepares a written summary of the task, and the facilitator, who ensures that all members participate;

- Assigning team members may be random, voluntary or for a specific purpose according to the objectives pursued;

- The work group, are tasks or forums, are supporting activities in a learning environment that involves reciprocity between the participants and set as a permanent attitude among group members, whose purpose can be learning all.

Expert $\rightarrow$ The consultant, in undertaking these categories, has an academic background, discipline and above all in the online training in the use of virtual platforms, to thus become a consultant, to solve problems, managerial, teamwork, have creativity, communication skills and learning and thinking skills.

The methods to achieve these competencies are changing as the training of people is also associated with a very important transformation on training time and space. Training time is becoming less defined and outside the formal training can occur at anytime and anywhere. The specific strategies that help to acquire a very precise, so that the support, guidance cognitive processes run media, communities of practice, among others, allow interactive presence. Thus, the choice of model and design of training is re-usable and therefore more economical.

\section{Cognitive Presence}

Cognitive presence includes part of what was proposed by Gunawardena, Lowe and Anderson (1997) in their categorization model for the analysis of interactions in the steps of: (a) social construction of knowledge, such as comparing information, (b) find the inconsistencies between the ideas, concepts or statements, (c) negotiating construction of knowledge, (d) agreed to provide, (e) construct new meanings, in general, learning-related skills.

The development of online content is reaching virtually all levels of education and all training modalities. In the past five years have increased the virtual campus, the online training programs, especially in higher education, both are playing significantly. A is amplitude of overlapping fields of application models available for work in these environments: lessons distributed educational systems to be used depends to a great extent on the training objectives and the context of use.

Despite the potential of Information Technologies and Communication in virtual training, the reality is not always as promising as it seems. In this sense, the increasingly widespread use of Internet is not having a formative influence and empowering new dimensions of learning. With few exceptions, their presence tends to impose an educational model focuses on content, shifting what is done in a face to a virtual environment. The proliferation of virtual campus and online courses is an example. It is, in many cases, innovative courses in the medium used but rarely introduce substantial innovations in the design approach or pedagogy (instructional design). 
Innovations in training do not necessarily have to be seen in distance learning but also in the face. In this sense, the fundamental interest lies in the use and optimization of technology. We consider the use of technology as a mediator of learning helps to supplement learning activities and proposals that can hardly be done in the classroom attendance.

The forums are mediators of learning; these tools are becoming more popular among academics, although its use is varied, ie as an element of debate, supporting the process of learning, sharing information among others. Our interest in this work was to analyze the educational possibilities of virtual forums on a specific university graduate, through meaningful learning strategies to construct meaning and collaborative learning.

Arango (2003) defined the forums as "a scenario of Internet communication, which fosters discussion, dialogue and consensus of ideas." These spaces can be maintained constant communication with people who are at considerable distances without having to agree on the network schedules. According to the descriptions of the Dimensions of Social Presence, Cognitive and Interactive, will work with the categories proposed by Yacci (2003), they are adapted and adjusted to the activity taking place in the discussion forums as well as the nomenclature used in the MGGI:

Message loop $\rightarrow$ It is a complete interactive loop, ie a person issues a message and is captured by a receiver that decodes it and sends a new message back to the issuer and is now receiving. Here, there is interactivity.

Content learning $\rightarrow$ In this category is important as related to the modification of structures of thought in it the student presents his activity as a learning strategy for distance learners. Yacci the subcategories (2003) identified for interactions related to learning content is identified with the stages identified by Piaget (1969) for the learning process: acquisition, development and restructuring.

- The category of knowledge acquisition refers to messages that resonate in a first level of learning, for which no structures or previous schemes that allow the organization of this new content as well as the creation of such containers in which after more knowledge can be integrated;

- The further category has been used to identify messages with a higher level than before, which is already pre-schemes for organizing the content, but in which there is no completed level of knowledge;

- The restructuring category refers to the highest level in the learning of content, it represents a student who has modified its previous structures and has been an assimilation and accommodation in their cognitive schemas.

Affective benefits $\rightarrow$ One of the benefits of interactivity is the emotional benefit that achieve the Participants in the discussion forums, since motivation plays an important role in learning, and the affective is caused primarily by the consultant and also by the students themselves Whether professor to student or one student to other student.

Mutually coherent $\rightarrow$ This category takes very closely the relationship between the initial message and the response, so that the response (feedback) issued by the receiving entity should not be distanced from the initial message from the CA, i.e. to consider that has been achieved mutual coherence is necessary to refer to the same subject.

Open circuit $\rightarrow$ Communication is issued without an addressee or mutual coherence or emotional benefit; they have no element of learning. Generally, these are messages that do not trigger reactions.

Also to measure these categories work with the following indicators:

(a) Interactivity: a message and is captured by a receiver that decodes it and sends a new message back to the issuer and is now receiving;

(b) These are identified with the stages identified by Piaget (1969) for the learning process: acquisition, development and restructuring;

(c) The motivation plays a role in learning and the affective is caused primarily by the consultant and also by the students themselves, whether professor-student or student-student;

(d) When the message is about the same subject;

(e) When not referred to the issue.

These items addressed and its relationship produce a given interaction, which undoubtedly will vary in a certain way, and therefore have values and may have degrees of measurement or have a certain range.

Thus, distance education, there are new elements to consider, one of them is the interaction between counselor, student and content, in which new communication technologies play a key role. From the social practices that place the interaction at the forefront of interest in the social and educational research, there have been changes both educational and communication.

In the case of MGGI, discussion forums are the space to perform this crucial practice in collaborative learning. After having established the categories to use, is passed to collect information from messages posted to forums sorting each of them in the established categories, they answer the research questions and compliance objectives.

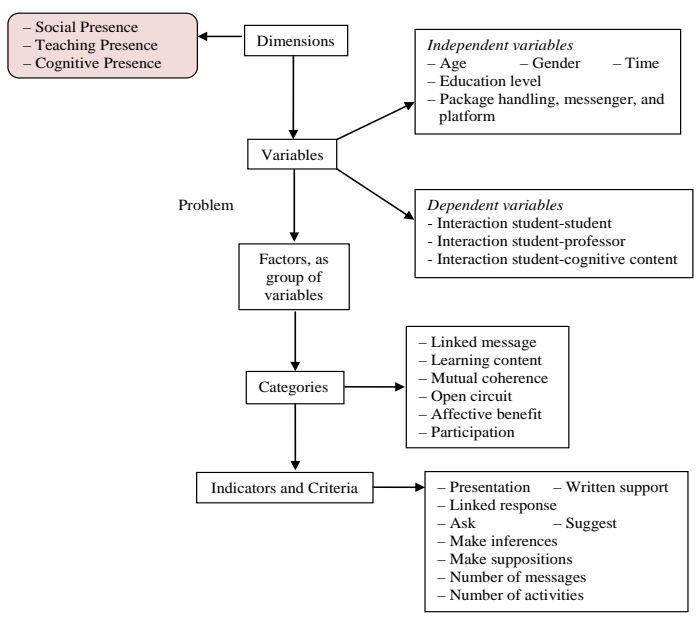

Figure 1. The above discussed can be illustrated in the scheme

\section{Research Questions}

What are the discussion interactions between MGGI students? What type, how to classify them, how these students construct the meaning of innovation? An investigation was conducted to answer these questions.

Supposed

If MGGI's students make discussion interactions between them about the innovation topic then there is a 
meaning construction and expected interactions are classified into three dimensions (social presence, interactive and cognitive).

Research Purposes

To identify the type of units to incoming students to MGGI activity in the forum called innovation for the discussion;

To classify discussion interactions between the new students of the MGGI;

To identify as students of the MGGI who construct the meaning of innovation

\subsection{The Research Method}

The research approach was qualitative, we used conversation analysis to identify dimensions which are included in messages and classify the type of message. Below is a brief description of the process used in this research:

1. Data were collected from all units of the students MGGI activity called innovation (virtual forum for discussion), seeking to recover prior knowledge that students have to enter and see if that expertise through interaction there is the construction of knowledge on the concept of innovation. Total posts in this forum were 47 units;

2. We performed a compilation of records of that forum. Copied and pasted the messages written on a document from Word program, units were compiled and listed all these messages according to the time of participation;

3. In another paper in Word was made an array with five columns, including dates (8, 9, 10, 11, 12 and 15 February 2011) of participation and are organized in chronological order messages according to the hour and minute participation of each student;

4. Transcript was prepared for analysis. Of all the records were selected text data that were useful, ie, they were the subject (innovation), which had no distracting text and took the full message as the unit of analysis. To respect the anonymity of the students took the decision not to write their names, were written as participante1, participante2 until participante15. The full record lines were numbered, included the dates, hours and minutes of interaction;

5. Reading the transcript $\rightarrow$ We performed a comprehensive initial reading of the transcript to select the data useful for research, become familiar with: the participants, their writing style, the content of the messages, who took the word (spoken in written form), who takes the lead group, among other things on the forum;

6. Defining the sample $\rightarrow$ As a forum for participation duration was eight days, it took the decision to include all records that talked about the issue. Of the 47 posts only 39 were selected because they were addressing the topic of innovation and all were written by students, the other 8 posts, 7 were discarded because they were trying but not side issues of innovation and posts 16 and 32 a copy that was sent to a fellow student so that the message 32 was removed from the analysis to avoid difficulties in reading and interpretation and respect the text-based chat. The consultant has only one intervention at the beginning, in the time of the activity for the debate and that message is not included within the 47 students total posts;
7. Analyzing the sample $\rightarrow$ Discussed elements of conversation analysis, with the contents of the sample (39 posts) was examined was the person who had the conversation of the subject, who left the subject (7 messages), which takes place (started as leader ), the sequence of those who answered and items related to the conversation / discussion (dimensions, categories and units of analysis); and

8. Theoretically contextualize the conversation analysis.

\section{Main Results}

During the activity for discussion, the group interacted full (15 students) contributed with 47 units, without the intervention of counsel (only the generic) not counted within the 47 messages. The first participation by the students was the February 8, 2011 at 9:59 am and the last post was February 15, 2011 at 13:19.

Table 1. All interventions by participant

\begin{tabular}{|c|c|}
\hline Participant Number & Total of Participations \\
\hline P1 & 3 \\
\hline P2 & 4 \\
\hline P3 & 3 \\
\hline P4 & 4 \\
\hline P5 & 4 \\
\hline P6 & 2 \\
\hline P7 & 6 \\
\hline P8 & 4 \\
\hline P9 & 3 \\
\hline P10 & 4 \\
\hline P11 & 2 \\
\hline P12 & 1 \\
\hline P13 & 3 \\
\hline P14 & 1 \\
\hline P15 & 3 \\
\hline Total & 47 \\
\hline
\end{tabular}

Note.- The participants are who posted a messages.

In the Table 1 was identified all the posted messages in the discussion forum called innovation (activity) incoming by MGGI's students. With this, one of the research questions was answered.

The analysis of transcripts of the full group discussions revealed that the posts 24, 26, 37, 39, 41, 43 and 46 were from other than the innovation issues, topics covered were collateral on organizational values, human so that those messages were deleted.

The message 32 is eliminated because it was a copy of the message 16 (this if it was considered in the analysis). The answers are bound to question the consultant generating plated were 7 (see Fig. 2), the black circle with a letter A inside represents the counselor, the other messages were linked to messages from their peers as shown in graph, it shows the communication network among the 15 participants of the forum, participants are represented by red circles and abbreviated to P1 for Participant 1, Participant 2 P2 and so on until the last participant (P15).

Participants answer the question by writing down what is innovative, express and present their ideas, contributed their views, in a first level students share information with 
the counselor and their peers, these responses are linked to different messages starting with the main question or the message of the first party, so you can see the size of the Teaching Presence (linked message) among participants.

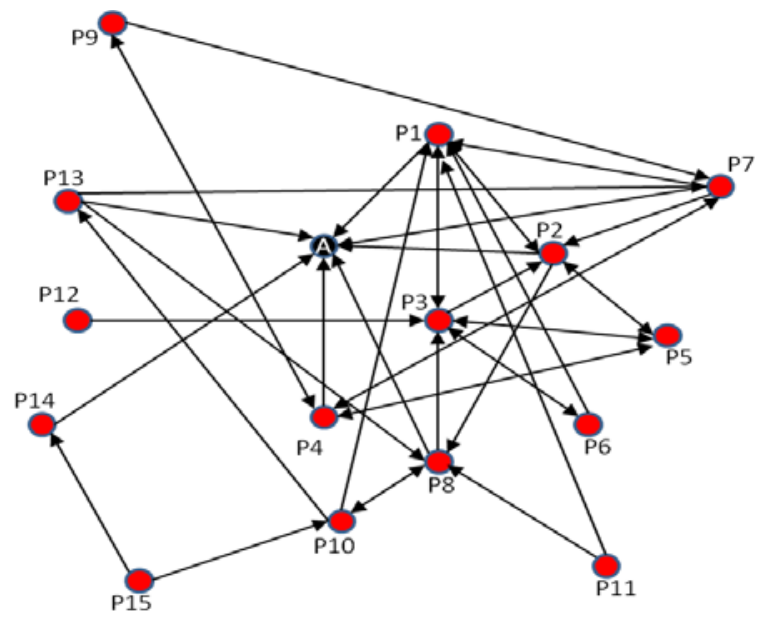

Figure 2. Sociogram of Shares

Note.- Sociogram of the shares of students in the Master of Management and Generation of Innovation: About the innovation topic.
In the Figure 2, "A" is the professor and is in a relationship with P1, P2, P3, P4, P5, P6, P7, P8, P9, P10, $\mathrm{P} 11, \mathrm{P} 12, \mathrm{P} 13, \mathrm{P} 14, \mathrm{P} 15$ (students / participants in the forum) and P1, P2,... communicate between them.

The Figure 2 is a communication network that resulted (Sociogram), is a representation of social links that a student has, illustrates the conversations in the forum called innovation. This graph drawing plots the structure of interpersonal relations in a MGGI group situation.

The type of interactions of discussion among new students of the Master of Creation and Innovation Management are of different types: identify areas of agreement and disagreement, support in writing, make reference to quotes and messages from their peers, bring new ideas, evaluate the participation of their peers, make thoughtful comments, use critical thinking, knowledge construction, among others.

The interactions were classified into three dimensions (interactive presence, cognitive and social). Of the 47 messages analyzed showed that 18 of them included three dimensions, 14 of them identified two dimensions that are present and could be the following combinations: interactive, cognitive and social cognitive, teaching and social, see Table 2 .

Table 2. Example of a classification of each message according to the dimension to which it belongs

\begin{tabular}{|c|c|c|c|c|c|}
\hline NumMessage & Part. Num. & \multicolumn{3}{|c|}{ Dimensions } & Deleted messages \\
\hline & & Three presences & Two presences & One presence & \\
\hline 1 & P1 & 1 teaching, cognitive and social & & & \\
\hline 2 & $\mathrm{P} 2$ & & & 1 teaching & \\
\hline 3 & P3 & 2 teaching, cognitive and social & & & \\
\hline 4 & P4 & & & 2 teaching, & \\
\hline 5 & P2 & & 1 teaching and cognitive & & \\
\hline 6 & P5 & & & 3 teaching & \\
\hline 7 & P2 & & 2 teaching and cognitive & & \\
\hline 8 & P5 & & 3 teaching and cognitive & & \\
\hline 9 & P4 & & 4 teaching and cognitive & & \\
\hline 10 & P6 & & 1 cognitive and social & & \\
\hline$\dot{ }$ & $\dot{v}$ & &. & &. \\
\hline 24 & P1 & & & & other topic \\
\hline
\end{tabular}

Note.- Messages from 15 participants

The Table 2 is an example about posted messages classified (discussion interactions between the new students of the MGGI). With this, one of the research questions was answered.

\section{Discussion}

The Information and Communications Technology (ICT), and specifically the online discussion forums provide tools that facilitate interaction among students, teachers and content. In this case, the learning activity (cognitive presence) is an autonomous and collaborative learning; participants within the proper context of virtuality in MGGI learning environment. Nevertheless, these alone sections will not guarantee completely the student's learning.

That is, these virtual tools requires teaching methods, implementing new skills such as instructional design adapt to contemplate the interaction as an essential activity for achievement target raised, and to achieve meaningful learning.

One ICT is the Moodle platform, this platform has an open methodology, has online forums but MGGI's course is not focuses only collaborative work, the activities developed by students allow them to achieve a level of meaningful learning. This type of learning, was implemented as the central approach in the instructional design, the student is considered the center of the teaching-learning process.

Based on this, develop an interaction group serves to knowledge construction, i.e. communications in context between: (a) students and teacher (teaching and social presence), (b) students and students (cognitive and social presence) and (c) student with contents, assignment (cognitive presence), resources and tools.

The social element was decisive for interaction, as witnessed by Teaching Presence Dimension. According to Moore and Anderson (2003) the consultant responsible for the course cause that students undertake social knowledge 
construction through a learning environment based on discussion activity as allowed students to have freedom and initiative to achieve their own goals as well as their participation in the forum.

In the course called Introduction to Virtual Technologies MGGI was observed that the interaction with the active participation of the 15 students, they create a dynamic interaction between task (activity for discussion about what innovation means), teacher and learner.

The students make meanings through the interactions (social, teaching and cognitive presence) with each other and with the environment they live sharing their perspectives. They generate meaning and knowledge from an interaction between their previous knowledge and their experiences, they constructing understanding through. This entails that students and instructors should develop an awareness of each other's viewpoints and then look to their own beliefs, standards and values, thus being both subjective and objective at the same time (Savery 1994).

\section{Conclusions}

We concluded that implemented the instructional design a discussion activity in online forum with MGGI students, propitiated meaningful learning, encouraged students to make autonomous and responsible for their own learning, for sharing objectives and activities. They understand that as part of the group participating in a virtual forum, have responsibilities to themselves, their peers and their context.

Their personal attitude fostered the active participation which contributed to the achievement of the purposes of the object of the forum and commitment to acquire with your group.

In this sense, we conclude that within the online forums in MGGI course, effective interaction takes place, this was evident in the Teaching Presence Dimension to view and analyze the types and number of messages produced by the students and the forum analyzed. As this complies with those reported by Hertz-Lazarowitz (as cited in Prendergast, 2003), who discusses the concept of interaction as a communicative situation between students and teachers, this author defines that to be a real interaction during learning processes should include four factors, which were observed in the forums MGGI in the course called Introduction to Virtual Technologies, should be performed:

- Cooperation to develop the activity in the forum.

- Support among students

- The relationship and communication between teacher and student.

- And communication unrelated to academic work (so called event social).

Then, the interactions conducted among MGGI students meet as a process of learning (teaching, social, cognitive presence) mediated activity proposed by Vygotsky (1987) and which performs an intrinsic collaborative condition of interactional, basic process in the teaching process collaborative-learning, which encourages you to rethink ideas, concepts, conflicts, investigate and learn new concepts.

\section{Acknowledgement}

The heading of the Acknowledgment section and the References section must not be numbered.

\section{References}

[1] Aires, L., Teixeira, A., Azevedo J., Gaspar M. \& Silva S. (2006). Alteridad $\mathrm{y}$ emociones en las comunidades virtuales de aprendizaje. Revista Electrónica Teoría de la Educación. Educación y Cultura en la Sociedad de la Información. Vol. 7. №2. Diciembre 2006. Retrived from

http://campus.usal.es/ teoriaeducacion/rev_numero_07_02/n7_02 _luisa_aires.pdf.

[2] Arango, M. (2004, abril). Foros virtuales como estrategia de aprendizaje. Revista Debates Latinoamericanos, No 2. Retrived from

http://www.rlcu.org.ar/revista/numeros/02-02-Abril2004/documentos/Arango.pdf.

[3] Anderson, T., Rourke, L., Garrison, D.R. \& Archer, W. (2001). Assessing teaching presence in a computer conferencing context. Journal of Asynchronous Learning Networks, (5)2. Retrived from http://www.aln.org/alnweb/journal/jalnvol5issue2v2.Htm.

[4] Bruner, J. S. (1996). The culture of education. Harvard University Press.

[5] García, C. y Perea, V. (2007). Comunicación y aprendizaje electrónico: la interacción didáctica en los nuevos espacios virtuales de aprendizaje. Revista de Educación, 343. Retrived from http://www.revistaeducacion.mec.es/re343/re343_17.pdf.

[6] Garrison, D. \& Anderson, T. (2005) Teaching Presence. In: D. R. Garrison \& T. Anderson (Ed.), El e-learning en el siglo XXI. Investigación y práctica (1a. ed., pp. 95-105). Barcelona, España: Ediciones Octaedro, S.L.

[7] Garrison, D. R., Anderson, T., \& Archer (2000) W. Critical inquiry in a text-based environment: Computer conferencing in higher education. The Internet and Higher Education, 2 (2-3), 1-19

[8] Gunawardena, Ch., Lowe, C. \& Anderson, T. (1997). Analysis of a global online debate and the development of an interaction analysis model for examining social construction of knowledge in computer conferencing. Journal of Educational Computing Research, 17(4), 397-431.

[9] Moore, M. J. \& Anderson, W. G.(2003). Handbook of Distance Education. Mahwah, NJ: Erlbaum

[10] Perera, V. \& Torres J. (2005). Análisis de las condiciones pedagógicas, sociales y cognitivas en los foros de discusión online. Retrived from

http://prometeo.us.es/idea/publicaciones/hugo/10.pdf.

[11] Piaget, J. (1969). The Mechanisms of Perception. London: Rutledge \& Kegan Paul.

[12] Savery, J. (1994). Science Curriculum and liberal education. Chicago University of Chicago Press.

[13] Vygotsky, L. (1987). Thinking and speech. En R.W. Rieber \& A. S. Carton (Eds.), The collected Works of L. S. Vygotsky, Volume 1: Problems of general psychology. New York: Plenum

[14] Wertsch, J. V., \& Stone, C. A. (1999). The concept of internalization in Vygotsky's account of the genesis of higher mental functions. Lev Vygotsky: Critical assessments, 1, 363-380.

[15] Yacci, M. (2003). Interactivity demystified: A structural definition for distance education and intelligent CBT. Educational Technology, 40(4), 5-16. 